\title{
Military Type III Anodizing: The Optimal Limit Within Hardening Process of Aluminium Alloy in a Near Zero Temperature
}

\author{
Ndaru Adyono ${ }^{1, *}$ W D Lestari ${ }^{2}$ Luluk Endahwati ${ }^{3}$ \\ ${ }^{1,2,3}$ Department of Mechanical Engineering, Faculty of Engineering, University of Pembangunan Nasional Veteran \\ Jawa Timur, 60294, Indonesia \\ *Corresponding author. Email: ndaru.adyono.tm@upnjatim.ac.id
}

\begin{abstract}
Hard anodization was a method that can enhance aluminium alloy surface characteristics by growing an aluminum anodic oxide (AAO) film on it surface. This method was very applicable to obtain a thick and hard coating. This process was carried out at galvanostatic-potentiostatic mode at high current densities $(\mathrm{j}=4.2 \mathrm{~A} / \mathrm{dm} 2)$, high target voltages (Vt $=30-60 \mathrm{~V})$ and low electrolyte temperature. Two sulfuric acid electrolyte was compared, the first solution was sulfuric acid $11 \%$ vol., the second one was sulfuric acid $11 \%$ vol. plus oxalic acid $1 \% \mathrm{wt}$, both of them was conditioned at $<5^{\circ} \mathrm{C}$. The maximum AAO film thickness and hardness obtained was $110.01 \mu \mathrm{m}$ and $400 \mathrm{HV}$. The increasment of target voltage was directly proportional to the increase in thickness and hardness of the AAO film. The results of this study could be synergized with the manufacturing process of aluminum alloy-based (Al6061) components at the product finishing stage. The logarithmic regression in the function of target voltage could be used to estimate film thickness and hardness of the films.
\end{abstract}

Keywords: Al6061, Hard Anodizing, Aluminium Anodic Oxide (AAO), Micro Vickers Hardness.

\section{INTRODUCTION}

Aluminum alloys has been widely used as a main materials in engineering world. Aluminum was a low cost, reliable and light weight material that had a high strength-to-weight ratio. However, aluminum alloys has problems of surface damage due to its softness. These deficiencies become an obstacle to wider application and advances of surface treatment are needed to overcome this problems [1].

Aluminium alloys surface characteristic can be enhanced electrochemically by anodization to grow a metal oxide on it surface. The layer formed is called the aluminum anodic oxide (AAO) films. This anodic coating can be produced on aluminium alloys by using a wide variety of electrolytes with $\mathrm{AC}$, DC, or a combination of both electrical current mode [2].

The coating industry categorizes AAO films into several types based on their mechanical properties and anodization process. Although there are editorial differences in standards such as ASTM B 580, MILITARY-A-8625F, etc., in general the AAO films is categorized into three types of anodization. Type I anodization for low current density (about $0.3-1.5$ $\mathrm{A} / \mathrm{dm}^{2}$ ) chromic acid based coatings and $1 \mu \mathrm{m}$ layer thickness. Type II anodization for sulfuric acid-based coatings with higher current densities (about 1.0 - 2.0 $\mathrm{A} / \mathrm{dm}^{2}$ ) and 3-18 $\mu \mathrm{m}$ thickness. Type III anodization for sulfuric acid-based coatings with high current densities (about $1.5-3.0 \mathrm{~A} / \mathrm{dm}^{2}$ ) and thickness above $25 \mu \mathrm{m}$ [3][4]

Type III anodizing in many scientific journals and engineering books is more popular called hard anodizing. Meanwhile, type I and II anodization is called mild anodization. Components that were treated with hard anodizing were generally components that really need wear or abrasion resistance on their surface; for example pistons, cylinders and gears. Hard anodizing coating was a surface treatment technique that optimally improves the surface resistance of aluminum when compared to mild anodization [5]. Hard anodizing can also increase the tribology performances of components due to the growth of a hard and compact oxide layer. Hard anodizing finds it large application in advanced structural engineering sectors as automotive, motorsport, aerospace and military [6]. 
The hard anodizing coating method was very applicable to obtain thick $(>50 \mu \mathrm{m})$ and hard $(>250 \mathrm{HV})$ AAO films with fast forming duration. This surface treatment method is an attractive method because it has a high-speed coating rate $(0.83-1.67 \mu \mathrm{m} / \mathrm{min})$ [7]. This AAO growth process was carried out at a high current density and electrolyte temperature which is conditioned close to zero degrees celsius. The use of electrolytes at very low temperatures was a key factor for producing a hard surface coating [8].

Research by Chu et al. and Schwirn et al. showed that power supply setup with the galvanostatic-potentiostatic mode at high current densities $\left(\mathrm{j}=2.5-100 \mathrm{~A} / \mathrm{dm}^{2}\right)$ and high target voltages $\left(\mathrm{V}_{\mathrm{t}}=27-80 \mathrm{~V}\right)$ at $1.8 \mathrm{M} \mathrm{H}_{2} \mathrm{SO}_{4}$ sulfuric acid electrolyte in low temperatures $\left(1^{\circ} \mathrm{C}\right)$ resulted an AAO film with a thickness in the range of 11.5 - $300 \mu \mathrm{m}$ using pure aluminum specimens (99.99\%). This approach was technically quite simple and costeffective [9][10]. Bensalah et al. compared the effect of anodization parameters on the AAO growing rate in AA1050 aluminum alloy specimens using a doehlert experimental design [11]. The optimization study showed that the optimum anodization conditions $\left(\mathrm{T}_{\text {electrolyte }} \leq 5.7{ }^{\circ} \mathrm{C}, \mathrm{j}=3 \mathrm{~A} / \mathrm{dm}^{2}, \mathrm{C}_{\text {sulfur }}=1,4 \mathrm{M}\right)$ resulted in a high AAO growing rate $(0.86 \mu \mathrm{m} / \mathrm{min})$ and a high films density $\left(3.12 \mathrm{~g} / \mathrm{cm}^{2}\right)$. Wu et al. also found that twostep anodization could effectively widen the applications of AAO films, either as high-precision nanoporous templates or as ultrathin functional materials [12].

This study was a surface treatment that refers to the galvanostatic-potentiostatic mode by $\mathrm{Chu}$ et al. and Schwirn et al. as an electrical setup during the anodization process. Anodization parameters, especially current density and electrolyte temperature, adapted the optimization research from Bensalah et al. Research on hard anodizing Al6061 aluminum alloy using galvanostatic - potentiostatic electrical mode is still not much done. Aluminum alloy $6 \mathrm{xxx}$ series was one of the recommended alumnium alloys that were suitable for use as the parent metal to produce a tough and corrosionresistant coating [13].

All aluminium alloys do not accept hard anodize coatings equally well. Hard anodize coatings on alloys with high copper or silicon content tends to be porous and not very hard. This study used a sulfuric acid based electrolyte because sulfuric acid was an electrolyte that can be used in almost all alloys with a copper content limit not exceeding 5.0\% and silicon not exceeding 7.0\% [13]. In addition, this research also tries to optimize the mechanical properties of the coating by adding variations of oxalic acid $\mathrm{H}_{2} \mathrm{C}_{2} \mathrm{O}_{4}$ into the electrolyte solution [14].

\section{METHOD}

The specimen used in this study was a cylindrical aluminum alloy Al061-T0 (no heat-treatment) with a length of $25 \mathrm{~mm}$ and a diameter of $10 \mathrm{~mm}$. The AAO film was grown only on the upper surface of the cylinder. Markers and non-sticky tape were used to chemically and electrically insulate the side and bottom surfaces of the cylinder. The upper surface of the specimen is smoothed with sandpaper (100-2000 grit size). Then chemically etched with $5 \% \mathrm{NaOH}$ solution at room temperature for two minutes and rinsed with distilled water.

The heat exchanger and agitation systems are combined into one in this research. Circulation in the heat exchange process is also used to maintain the solubility of ions $\left(\mathrm{Al}^{3+}, \mathrm{O}^{2-}\right)$ so that the electrolyte solution remains homogeneous. The circulating temperature of the solution was kept low $<5^{\circ} \mathrm{C}$ during the anodization process. Electrical system uses a two-step electricity, the condition of a constant current (galvanostatic) and constant voltage (potensiostatic).

The schematic diagram of the tool is shown in Fig. 1. The anodization process is an exothermic reaction which causes the surface of the coating to heat up and heat up the electrolyte solution. During the coating process, the electrolyte solution is circulated to the heat exchanger system. Heat is dissipated from the copper coil to the cooling medium. The cooled electrolyte then returns to the electrolyte bath.

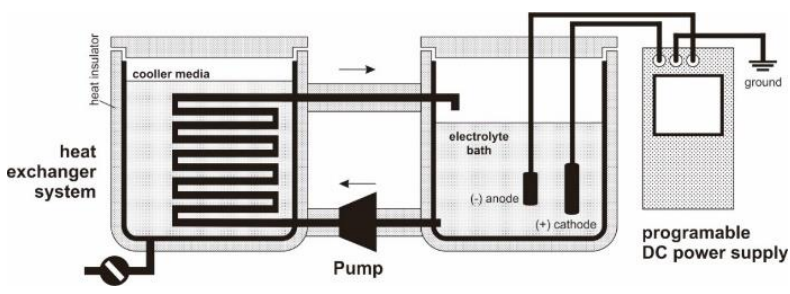

Figure 1 Schematic for hard anodizing surface treatment

The electrolyte solution is divided into two variations. The first variation (1) was sulfuric acid $11 \%$ vol. Dilution is carried out by slowly dissolving $224.5 \mathrm{~mL}$ of sulfuric acid $98 \%$ vol into $2 \mathrm{~L}$ of distilled water. The second variation (2) was sulfuric acid $11 \%$ vol plus oxalic acid $1 \%$ wt. Dilution is carried out by slowly dissolving 224.5 $\mathrm{mL}$ of sulfuric acid $98 \%$ vol into $2 \mathrm{~L}$ of distilled water plus 20 grams of oxalic acid powder.

The anodization process begins with a galvanostatic condition at $4.2 \mathrm{~A} / \mathrm{dm}^{2}$ then switch to potentiostatic when it reaches the target voltage $\mathrm{V}_{\mathrm{t}}$ and then maintained until the current density decreased to $1.0 \mathrm{~A} / \mathrm{dm}^{2}$. The target voltage consists of three variations 30, 40 and 60 Volts. Voltage, current and electrolyte temperature profiles were observed every minute using voltmeter, ammeter and thermometer.

The surface morphologies of the hard-anodized specimen at different target voltages were observed by Optical Microscopy (OM). The cross section of developed oxide film was observed by Optical 
Microscopy to obtain the coating thickness [15]. The micro-harnesses of the hard-anodized coating were observed with Micro Vickers method. The surface defect were observed by FE-SEM.

\section{RESULT AND DISCUSSION}

\subsection{Aluminium Alloy Al6061-T0 Composition.}

Table 1. Alloy composition wt\% of Al 6061 T0 [16]

\begin{tabular}{cccccc}
\hline Component & Wt. \% & Component & Wt. \% & Component & Wt. \% \\
\hline $\mathrm{Al}$ & $95.8-98.6$ & $\mathrm{Mg}$ & $0.8-1.2$ & $\mathrm{Si}$ & $0.4-0.8$ \\
$\mathrm{Cr}$ & $0.04-0.35$ & $\mathrm{Mn}$ & Max 0.15 & $\mathrm{Ti}$ & Max 0.15 \\
$\mathrm{Cu}$ & $0.15-0.4$ & $\mathrm{Fe}$ & 0.7 & $\mathrm{Zn}$ & Max 0.25 \\
\hline
\end{tabular}

\subsection{Ions Transport Mechanism}

Electrochemical anodization of Al6061-T0 aluminium alloys to form thick oxide films has been carried out. Anodization was an electro-chemical process which can be described as a closed electrical circuit. Metal oxide formation reactions can occur through dissolution of anodic metals to form suitable cations followed by reactions between metal cations and ionic oxygen [17]. The electric charge carriers that flowing through the AAO film were $\mathrm{Al}^{3+}$ and $\mathrm{O}_{2}^{-}$. The final reaction of aluminum oxidation:

$$
2 \mathrm{Al}^{3+}+3 \mathrm{H}_{2} \mathrm{O} \rightarrow \mathrm{Al}_{2} \mathrm{O}_{3}+6 \mathrm{H}^{+}+6 e^{-}
$$
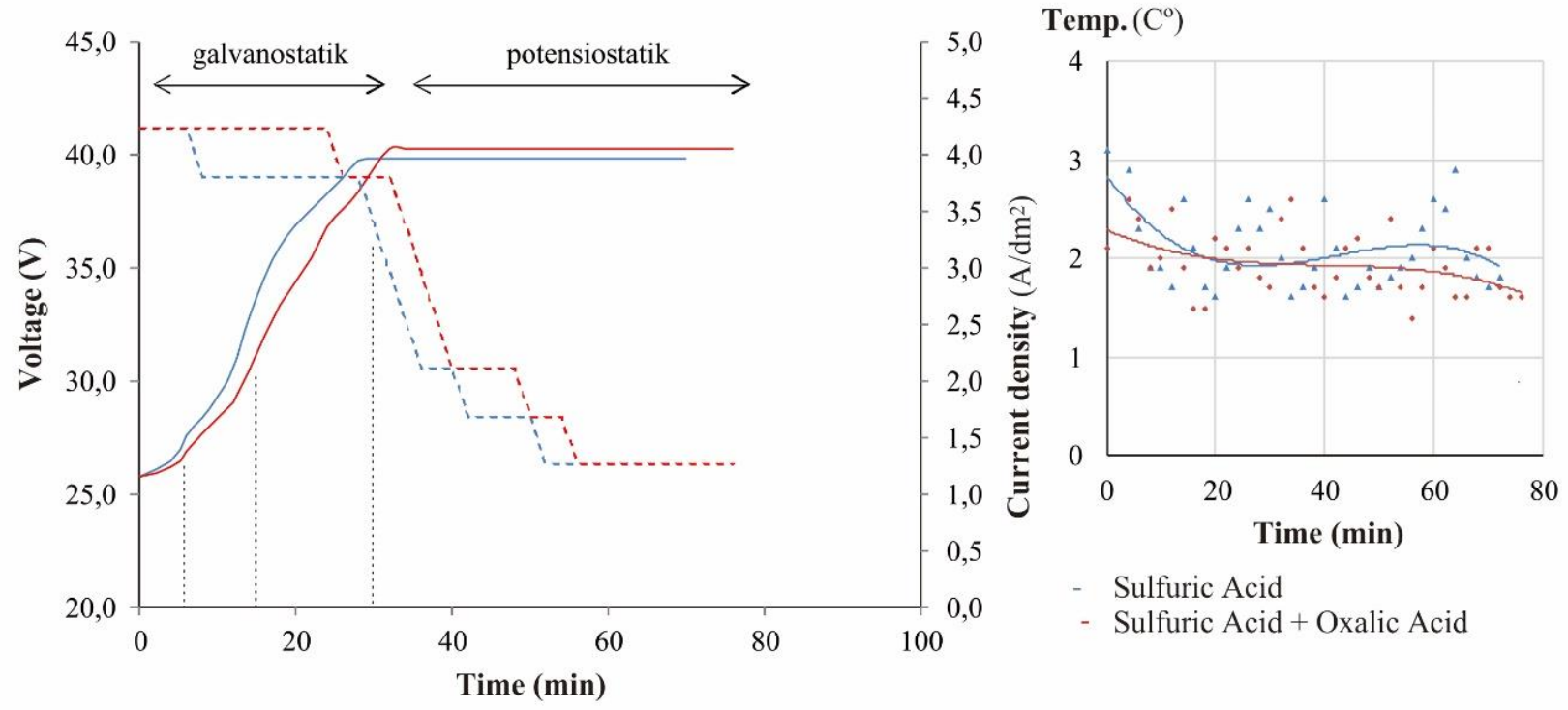

Sulfuric Acid

Sulfuric Acid + Oxalic Acid

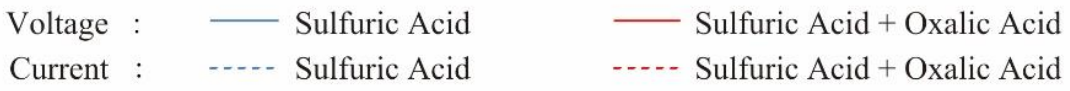

Figure 2 Electrical profile (a) and temperature profile (b) during the hard anodizing process at the target voltage $\mathrm{V}_{\mathrm{t}}=$ $40 \mathrm{~V}$ 


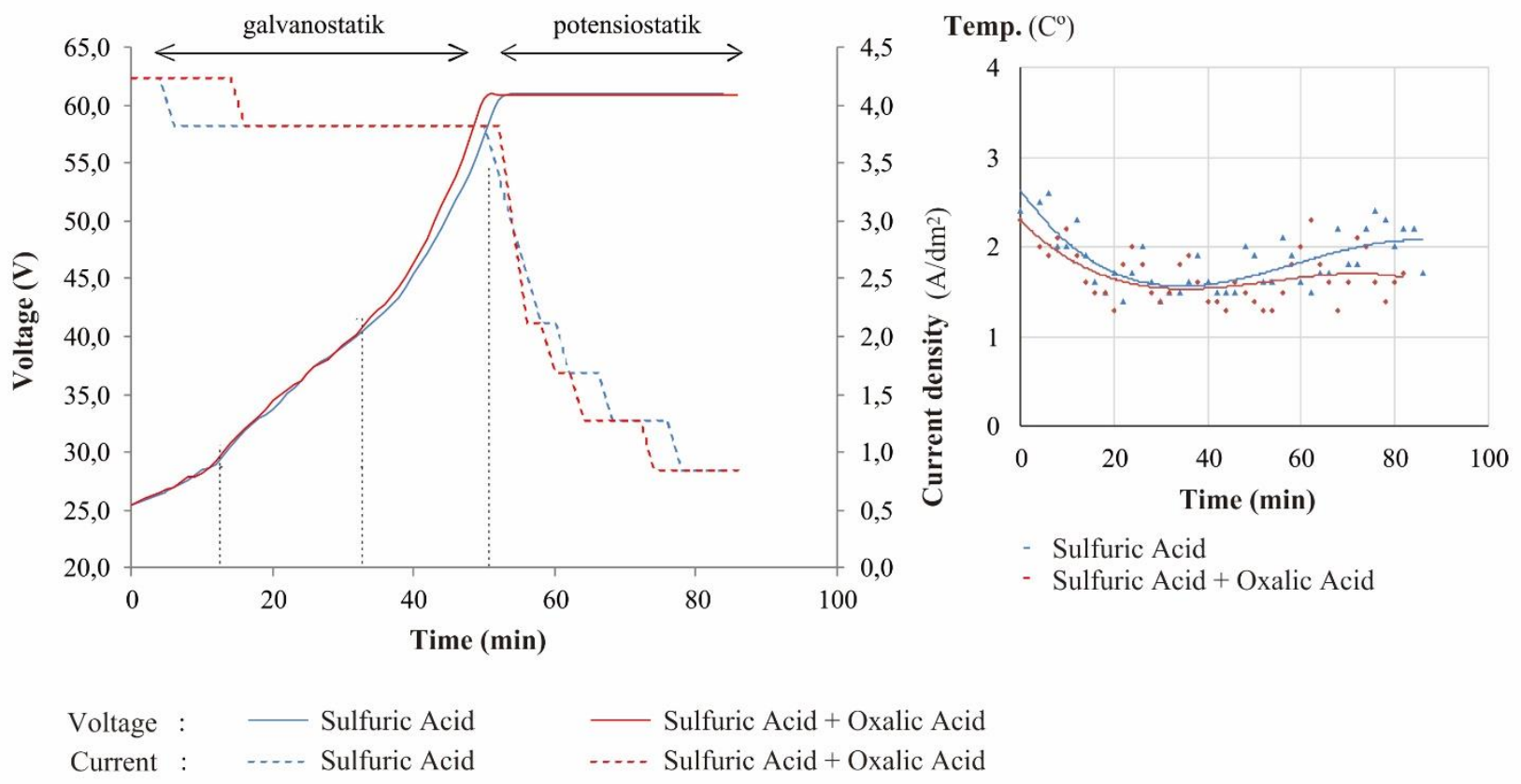

Figure 3 Electrical profile (a) and temperature profile (b) during the hard anodizing process at the target voltage $\mathrm{V}_{\mathrm{t}}=$ $60 \mathrm{~V}$

There was a slight difference in the electrical profile in Fig. 3 (a) on the target voltage parameter $\mathrm{V}_{\mathrm{t}}=60 \mathrm{~V}$. The current density in the $11 \%$ vol sulfuric acid electrolyte with the addition of $1 \%$ wt oxalic acid (red stripe) at the 5 to 55 minute was higher than the current density in the $11 \%$ vol sulfuric acid electrolyte (blue stripe), However, from the 55 minute till the end of the anodization, the current density in the $11 \%$ vol sulfuric acid electrolyte with the addition of $1 \%$ wt oxalic acid (red stripe) was lower than the current density at anodization in the $11 \%$ vol sulfuric acid electrolyte (blue stripe line).

\subsection{AAO Films Growth}

The relationship between the target voltage and thickness in Fig. 4 shows that the variation of $1 \% \mathrm{wt}$ addition of oxalic acid was good for use at target voltages below $50 \mathrm{~V}$. The use of target voltage above $50 \mathrm{~V}$ results in reduction $\Delta$ in film thickness. The use of voltages above $50 \mathrm{~V}$ was more suitable for variations of the $11 \%$ vol sulfuric acid electrolyte without the addition of $1 \%$ wt oxalic acid.

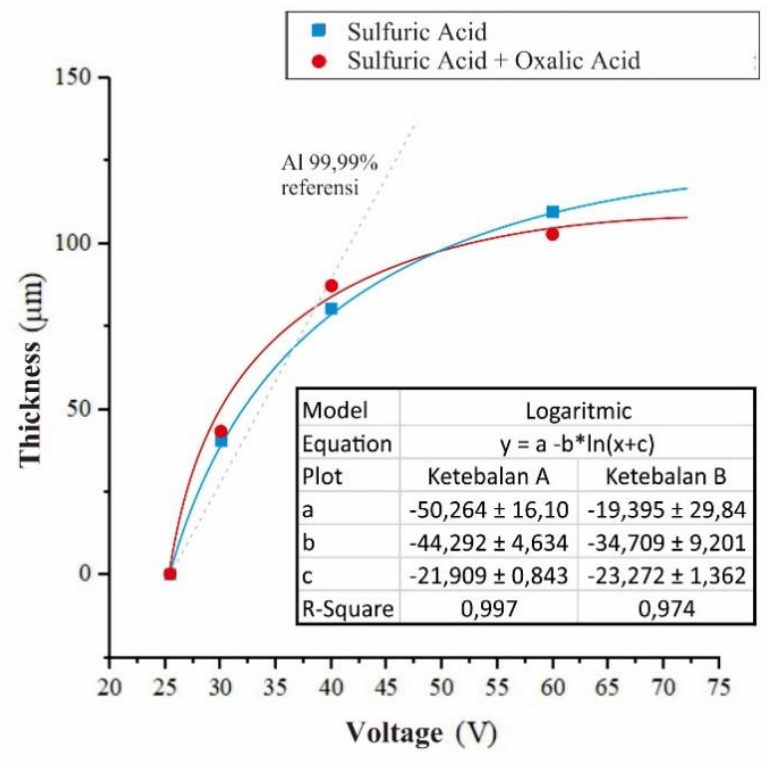

Figure 4 Plot $V_{t}$ target voltage vs thickness 


\subsection{The Micro-Hardness of AAO Films}

The AAO film increases its hardness significantly as the target voltage increases. The relationship of target voltage with the thickness and hardness was shown in Fig. 6. The diagram with a solid color bar shows the

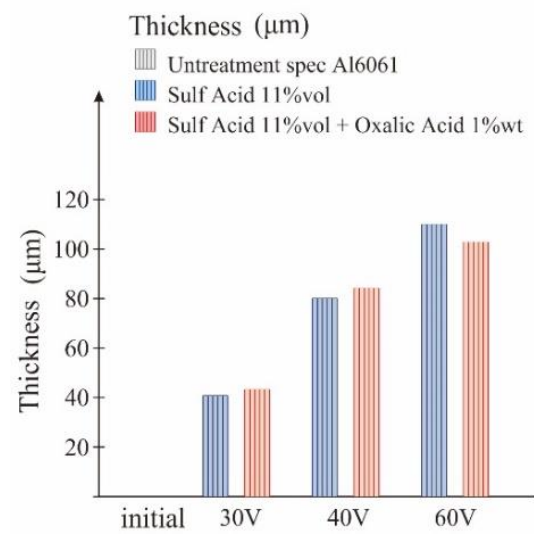

hardness value, while the shaded colored bars show the thickness value. The blue color shows speciments in $11 \%$ vol $\mathrm{H}_{2} \mathrm{SO}_{4}$ sulfuric acid electrolyte, while the red color shows speciments in $11 \%$ vol $\mathrm{H}_{2} \mathrm{SO}_{4}$ sulfuric acid electrolyte with the addition of $1 \%$ wt $\mathrm{H}_{2} \mathrm{C}_{2} \mathrm{O}_{4}$ oxalic acid.

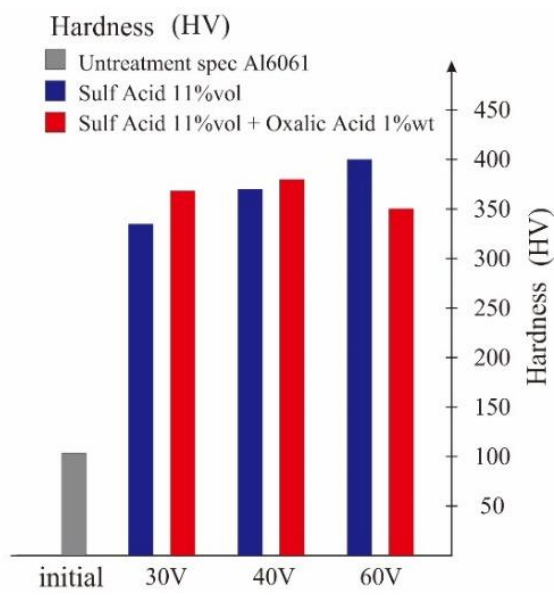

Figure 6 Chart of AAO Film thickness and hardness in different electrolyte solutions and target voltages.

The initial voltage $(25 \mathrm{~V})$ in Fig. 6 was the initial electrical breakdown voltage. In the initial voltage condition, it is assumed that the AAO film has not been formed and the hardness value same as the initial specimen hardness value 103.5 HV. The thickness and hardness of the films were directly proportional to the increase in target volltage $\mathrm{V}_{\mathrm{t}}$.

Films optimization does not occur at target voltage $60 \mathrm{~V}$. In fact, this optmization was resulting lower thickness and hardness than the variation without the addition of oxalic acid. This phenomenon may occur because the addition of oxalic acid increases the current density profile and results in too high stress on the oxide columns, especially in the target voltage $60 \mathrm{~V}$. Observation of FE-SEM images with a magnification of 100,000x in Figure 5(b) showed cracks at a scale of 1

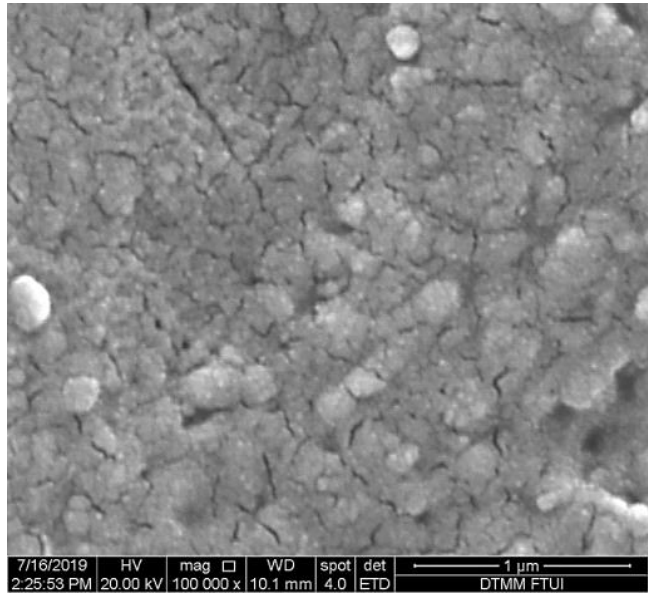

(a) micron on the surface of the layer. When compared with the anodizing in variations without the addition of oxalic acid in Figure 5(a), at the same target voltage parameter. No cracks were found on the 1 micron scale on the films surface. This FE-SEM image confirms that the stress release on anodization with sulfuric acid variation is better than that with the addition of oxalic acid.

The films properties in many heat treated aluminum alloys are seriously affected by intermetallics, microstructural and compositional inhomogeneities as mentioned in section 3.1. Furthermore, distorted distributions of electric field are possible and they can lead to inhomogeneous oxide growths. Through the optimization of electrolyte, current density, voltage and other variables a good compromise between hardness, compactness and low defectiveness can be achieved.

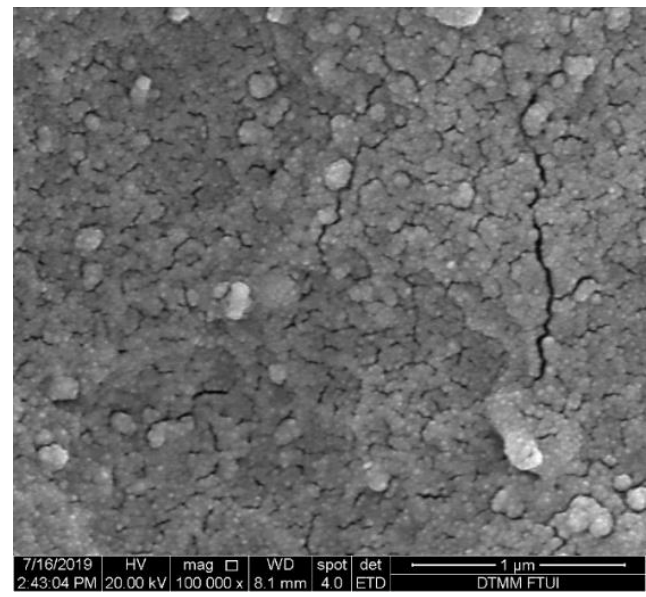

(b)

Figure 5 FE-SEM images of AAO films $\mathrm{V}_{\mathrm{t}}=60 \mathrm{~V}$ with 100.000 magnification. (a) sulfuric acid $\mathrm{H}_{2} \mathrm{SO}_{4} 11 \%$ vol electrolyte. (b) sulfuric acid $\mathrm{H}_{2} \mathrm{SO}_{4} 11 \%$ vol + oxalic acid $\mathrm{H}_{2} \mathrm{C}_{2} \mathrm{O}_{4} 1 \%$ wt electrolyte. 


\section{CONCLUSION}

The characteristics of AAO films were influenced by the type of aluminium alloys and the anodizing conditions. The films thickness vary with the anodizing parameters. The optimum anodizing target voltage for each electrolyte are $60 \mathrm{~V}$ for $11 \% \mathrm{vol}_{2} \mathrm{SO}_{4}$ sulfuric acid electrolyte and $40 \mathrm{~V}$ in $11 \%$ vol $\mathrm{H}_{2} \mathrm{SO}_{4}$ sulfuric acid electrolyte with the addition of $1 \%$ wt $\mathrm{H}_{2} \mathrm{C}_{2} \mathrm{O}_{4}$ oxalic acid. The maximum film thickness in this study was $110.01 \mu \mathrm{m}$ which was produced using $11 \%$ vol sulfuric acid electrolyte with current density $4.2 \mathrm{~A} / \mathrm{dm} 2$, target voltage $60 \mathrm{~V}$ and electrolyte temperature $\sim 2^{\circ} \mathrm{C}$.

The target voltage variations $(30 \mathrm{~V}, 40 \mathrm{~V}$ and $60 \mathrm{~V})$ was directly proportional to the increase in thickness and hardness. Increasing the target voltage of $30 \mathrm{~V}, 40 \mathrm{~V}$ and $60 \mathrm{~V}$ at the variation of the sulfuric acid electrolyte of $11 \%$ vol produced AAO films with a hardness of 334.8 $\mathrm{HV} ; 370.0 \mathrm{HV}$ and $400.0 \mathrm{HV}$. While increasing the target voltage of $30 \mathrm{~V}, 40 \mathrm{~V}$ and $60 \mathrm{~V}$ in the electrolyte with the addition of $1 \%$ wt oxalic acid produces films with a hardness of $368.5 \mathrm{HV} ; 380.0 \mathrm{HV}$ and $350.4 \mathrm{HV}$. From films thickness and hardness of all variable in this study, the anodized layer meets the standard specification MILA-8625F and ASTM B 580.

\section{ACKNOWLEDGMENT}

The authors acknowledge financial support under the University Pembangunan National Veteran Jawa Timur for this conference and publication. The author also express his thanks to reviewers and proofreaders, or technicians who help prepare equipment set-ups in his research.

\section{REFERENCES}

[1] H. Dong, Surface Engineering of light alloys, I. Woodhead Publishing Limited, 2010.

[2] V. F. Henley, Anodic oxidation of aluminium and Its Alloy, 1st ed. Pergamon Press, 2011.

[3] Department of Defense USA, "MIL-A-8625F Military Specification Anodic Coatings for Aluminum and Aluminum Alloys," 2003.

[4] ASTM, "ASTM B580-79 Standard Specification for Anodic Oxide Coatings on Aluminum," 2000.

[5] B. Wielage, G. Alisch, T. Lampke, and D. Nickel, "Anodizing - a key for surface treatment of aluminium," Key Eng. Mater., vol. 384, pp. 263281, 2008.

[6] M. Bononi, M. Conte, R. Giovanardi, and A. Bozza, "Hard anodizing of AA2099-T8 aluminum lithium copper alloy: Influence of electric cycle, electrolytic bath composition and temperature," Surf. Coat. Technol., vol. 325, pp. 627-635, 2017.

[7] W. Lee, R. Ji, U. G. Gosele, and K. Nielsch, "Fast fabrication of long-range ordered porous alumina membranes by hard anodization," Nat. Mater., vol. 5, no. 9, pp. 741-747, 2006.

[8] W. J. Stepinowski, A. Nowak-st, A. Presz, T Czujko, and R. A. Varin, "The effects of time and temperature on the arrangement of anodic aluminum oxide nanopores," Mater. Charact., vol. 1, pp. 1-9, 2014

[9] S. Z. Chu, K. Wada, S. Inoue, M. Isogai, and A. Yasumori, "Fabrication of ideally ordered nanoporous alumina films and integrated alumina nanotubule arrays by high-field anodization," $A d v$. Mater., vol. 17, no. 17, pp. 2115-2119, 2005.

[10] K. Schwirn, W. Lee, R. Hillebrand, M. Steinhart, K. Nielsch, and U. Gösele, "Self-Ordered Anodic Aluminum Oxide Formed by," ACSNANO, vol. 2, no. 2, pp. 302-310, 2008.

[11] W. Bensalah, M. Feki, M. Wery, and H. F. Ayedi, "Thick and Dense Anodic Oxide Layers Formed on Aluminum in Sulphuric Acid Bath," J. Mater. Sci. Technol., vol. 26, no. 2, pp. 113-118, 2010.

[12] J. Wu et al., "Electrochemistry Communications Ultra-slow growth rate: Accurate control of the thickness of porous anodic aluminum oxide films," Electrochem. commun., vol. 109, no. November, pp. 6-10, 2019.

[13] ASM International Handbook Committee, ASM Handbook Vol. 5 Surface Engineering, 9th ed. ASM International, 1994.

[14] E. Febriyanti, "Optimasi Proses Pelapisan Anodisasi Keras,” Maj. Metal., vol. 5, pp. 109-116, 2011.

[15] ASTM, “ASTM B487-85 Standard Test Method for Measurement of Metal and Oxide Coating Thickness by Microscopical Examination of a Cross Section," 1997.

[16] ASM Aerospace Specification Metal Inc, "Aluminum 6061-T6; 6061-T651." [Online]. Available:

http://asm.matweb.com/search/SpecificMaterial.as p?bassnum=MA6061T6. [Accessed: 01-Jan-2018].

[17] J. M. Runge, The Metallurgy of Anodizing Aluminum. Chicago, USA: Springer, 2017. 